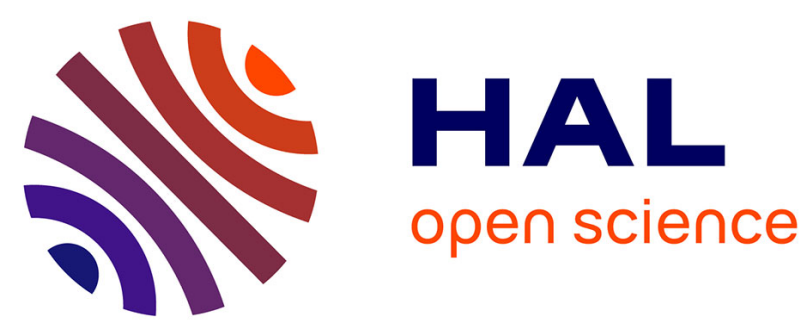

\title{
Prognostic value of longitudinal strain and ejection fraction in Friedreich's ataxia
}

\author{
L. Legrand, C. Heuze, A. Diallo, M.L. L Monin, C. Ewenczyk, E. Vicaut, G. \\ Montalescot, R. Isnard, A. Durr, F. Pousset
}

\section{- To cite this version:}

L. Legrand, C. Heuze, A. Diallo, M.L. L Monin, C. Ewenczyk, et al.. Prognostic value of longitudinal strain and ejection fraction in Friedreich's ataxia. International Journal of Cardiology, 2021, 330, pp.259-265. 10.1016/j.ijcard.2021.02.032 . hal-03181274

\section{HAL Id: hal-03181274 \\ https://hal.sorbonne-universite.fr/hal-03181274}

Submitted on 25 Mar 2021

HAL is a multi-disciplinary open access archive for the deposit and dissemination of scientific research documents, whether they are published or not. The documents may come from teaching and research institutions in France or abroad, or from public or private research centers.
L'archive ouverte pluridisciplinaire HAL, est destinée au dépôt et à la diffusion de documents scientifiques de niveau recherche, publiés ou non, émanant des établissements d'enseignement et de recherche français ou étrangers, des laboratoires publics ou privés. 


\section{Prognostic value of longitudinal strain and ejection fraction in Friedreich ataxia}

L. Legrand $d^{1.3 .5}$, C. Heuze ${ }^{1}$, A. Diallo ${ }^{4.5}$, M.L. Monin², C. Ewenczyk ${ }^{2}$, E. Vicaut ${ }^{4.5}$ G.

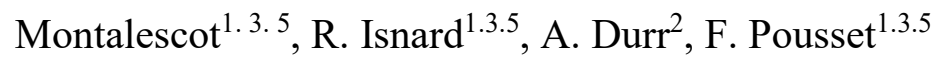

${ }^{1}$ Sorbonne Université, Cardiology Department, AP-HP, Pitié-Salpêtrière University Hospital Paris, France

${ }^{2}$ Sorbonne Université, Institut du Cerveau et de la Moelle épinière (ICM), AP-HP, INSERM, CNRS, Pitié-Salpêtrière University Hospital, Paris, France

${ }^{3}$ ICAN (Institute for Cardiometabolism and Nutrition), Pitié-Salpêtrière University Hospital, Paris, France

${ }^{4}$ URC Lariboisière University Hospital, Paris, France

${ }^{5}$ ACTION (Allies in Cardiovascular Trials Initiatives and Organized Networks) Group,

\section{Corresponding author: Dr Francoise Pousset}

Département de Cardiologie. Hôpital de la Pitié Salpêtrière. 47 boulevard de l'Hôpital. 75651 Paris Cedex 13 France. Phone: +33 1421630 14; email: f.pousset@aphp.fr

\section{Author contributions}

- Conception: F. Pousset

- Acquisition of the data: L. Legrand, C. Heuze, F. Pousset A. Durr, C. Ewenczyk, M.L. Monin - Analysis and interpretation of the data: C. Heuze, A. Durr, R. Isnard, L. Legrand, M.L. Monin, and F. Pousset

- Critical revision of the manuscript: All authors reviewed and revised the manuscript

- Statistical analysis: A. Diallo, E. Vicaut

\section{Conflict of interest:}

L. Legrand, C. Heuze, M.L. Monin, C. Ewenczyk, R. Isnard, C. Heuze, A. Diallo, E. Vicaut, G. Montalescot, A. Durr, and F. Pousset declare that they have no potential conflicts of interest that might be relevant to this work

Funding French Friedreich Ataxia Association (AFAF)

$\underline{\text { Key words: }}$ Friedreich's ataxia, prognosis, myocardial strain, cardiomyopathy 


\section{Abbreviations}

$\mathrm{ECG}=$ electrocardiogram

$\mathrm{FA}=$ Friedreich's ataxia

LS = Longitudinal strain

$\mathrm{LV}=$ left ventricle

LVDD = left ventricular end diastolic diameter

$\mathrm{LVEF}=$ left ventricular ejection fraction

LVSD $=$ left ventricular end systolic diameter

$\mathrm{PWT}=$ posterior wall thickness

$\mathrm{RWT}=$ relative wall thickness

SWT $=$ septal wall thickness

GAA = guanine-adenine-adenine trinucleotide 


\section{HIGHLIGHTS}

- Longitudinal strain correlates with the length of both alleles of the FXN gene in Friedreich Ataxia (FA)

- Longitudinal strain (LS) is a strong prognostic factor in univariate analysis in FA

- LS is not an independent predictor of mortality when LVEF is included in the analysis in FA patients

- The role of longitudinal strain in the management of FA patients remains to be defined 


\section{Abstract}

Background Friedreich's ataxia (FA) is a rare autosomal recessive mitochondrial disease most commonly due to a triplet repeat expansion guanine-adenine-adenine (GAA) in the FXN gene. Cardiac disease is the major cause of death, patients with reduced left ventricular ejection fraction (LVEF) having the worse prognosis. Longitudinal strain (LS) appeared to be a better predictor of outcome than LVEF in different diseases. We compared the prognostic value of LS measured from the 4 chambers view to LVEF.

Methods From 2003 to 2017 consecutive patients with FA were included and LS analysis was retrospectively performed.

Results We studied 140 patients, with a median age of 34 (26-41) years (Q1-Q3) with age at onset of 14 (11-19) years and GAA repeats on the shorter allele of 600 (467-783) pb. Mean LS was $19.9 \pm 5.0 \%$ and LVEF $64 \pm 8 \%$. After a mean follow-up of $7.4 \pm 3.9$ years, 14 patients died. In univariate Cox analysis, all-cause mortality was associated with: LS (HR 0.83; 95\%CI, 0.75-0.91, $\mathrm{p}=0.0002)$, LVEF (HR 0.30; 95\%CI, 0.19-0.49, $\mathrm{p}<0.0001)$, GAA repeats on the shorter allele (HR 1.29; 95\%CI, 1.10-1.51, $\mathrm{p}=0.002)$, age at onset (HR 0.87; 95\%CI, 0.77-0.98, $\mathrm{p}=0.018)$, LVSystolic Diameter (HR 1.17; 95\%CI, 1.09-1.26, $\mathrm{p}<0.0001)$, LVMass index (HR 1.02; 95\%CI, 1.00-1.04, p=0.027), and LVDiastolic Diameter (HR1.12; 95\%CI, 1.01-1.23, $\mathrm{p}=0.028)$. In multivariate analysis, LVEF was the only independent predictor of mortality (HR $0.41 ; 95 \% \mathrm{CI}, 0.23-0.74, \mathrm{p}=0.0029)$.

Conclusion In FA, LS was not an independent predictor of mortality, LVEF remained the only independent predictor in the present study. 


\section{INTRODUCTION}

Friedreich ataxia (FA) is an inherited autosomal recessive mitochondrial disorder and the most frequent inherited ataxia. It is characterized by progressive spinocerebellar ataxia, auditory and visual neuropathy, scoliosis and extra neurological effects such as diabetes, and cardiomyopathy. First symptoms often occur during adolescence or occasionally later in life. FA is in most cases caused by a homozygous guanine-adenine-adenine (GAA) trinucleotide expansion in the frataxin $(F X N)$ gene, which encodes frataxin, a mitochondrial protein involved in iron metabolism.[1-3] Longer GAA expansions are associated with earlier symptom onset and increased severity of the neurologic and cardiac disease.[3, 4]

Cardiac disease is the major cause of premature mortality in FA: congestive heart failure and supraventricular arrhythmia are the most frequent cardiac complications.[5-7]. Left ventricular ejection fraction (LVEF) has been shown to be an independent predictor of prognosis in FA.[6] Assessment of myocardial deformation using two-dimensional (2D) speckle tracking echocardiography has emerged as a method for the assessment of myocardial function. Global longitudinal strain (GLS) that reflects the longitudinal percentage deformation of all myocardial segments in the apical views has been validated as an index for global LV function. [8,9] Subtle LV dysfunction can be detected by this technique in a number of circumstances, even when LVEF is normal.[10] Furthermore, GLS appeared to be a stronger predictor of outcome compared to LVEF in different diseases, particularly in individuals with preserved ejection fraction.[11] In FA, reduced LV long axis function has been reported using Tissue Doppler imaging [12], and longitudinal strain in adult subjects with a normal LVEF [13], and has also been reported in cohorts of adults and children which included subjects with a reduced LVEF.[7, 14]

The objective of the present study was to compare the prognostic value of longitudinal strain and of LVEF in a large cohort of adult FA patients. 


\section{METHODS}

\section{Population}

We studied unselected genetically confirmed FA subjects evaluated from February 2003 through November 2017 in the Department of Cardiology (Pitié-Salpêtrière University Hospital, Paris, France), who had digitally-acquired baseline echocardiographic images, stored in 2D DICOM file formats to retrospectively assess myocardial strain. If a patient had several exams, the oldest was studied. The Institut National de la Santé et de la Recherche Médicale (INSERM) approved the study. Informed written consent was given in accordance with the law and local ethical regulations.

\section{Outcome of interest}

Follow-up data were obtained in May 2018 by clinical visits, or telephone interviews with the patient or relative, or by mail. Death, cardiac arrhythmia, heart failure and stroke were recorded. When contact with a patient or the family was not possible, the date of death was obtained from the French national registry of deaths. All-cause mortality was the endpoint.

\section{Neurological evaluation}

Neurological assessment was performed by a neurologist within three months of cardiac evaluation, and was assessed using the SARA score (Scale for the Assessment and Rating of Ataxia), a semi-quantitative scale developed to assess ataxia with values from 0 (no ataxia) to 40 (most severe ataxia)[15] and eight items assessing stance, sitting, speech disturbances, finger chase, dysmetria, nose-finger test, tremor, fast alternating hand movements, and heel-shin slide. Cardiac evaluation-including clinical evaluation, standard 12-lead electrocardiography, and standard transthoracic echocardiography- was performed on the same day.

\section{Electrocardiogram (ECG)}

A 12-lead surface resting ECG was recorded at $25 \mathrm{~mm} / \mathrm{s}$ and $10 \mathrm{~mm} / \mathrm{mV}$ and analyzed blinded to the echocardiographic data by one experienced cardiologist (LL). Repolarization was 
considered abnormal in the presence of negative $T$ waves $(\geq 0.1 \mathrm{mV})$ or flat $\mathrm{T}$ waves in at least two leads, except V1 and V2 in the absence of bundle branch block.

\section{Echocardiography}

All studies were performed on standard commercially available echocardiographic systems (Acuson C256, Siemens Company, Mountain view, USA), Vivid 7 and E9 (General Electric Company, Horten, Norway) by the same expert cardiologist (FP) blinded to genetic data. Standard techniques were used to obtain M-mode, 2-dimensional, and Doppler measurements in accordance with the recommendations of the American Society of Echocardiography. Each measure was the mean of three measurements.[16] Left ventricular (LV) end diastolic diameter (LVDD), LV end systolic diameter (LVSD), septal wall thickness (SWT), and posterior wall thickness (PWT) were obtained in the parasternal long axis view from an M-mode acquisition. Relative wall thickness (RWT) was defined as SWT+PWT/LVDD, and a concentric remodeling pattern as RWT $>0.42$.[17] Left ventricular mass index (LVMi) was obtained from M-mode and normalized for body surface area (ASE convention). Left ventricular ejection fraction (LVEF) was calculated using the bi-plane Simpson's disk method.[16] The peak E and A waves were measured from the pulsed wave Doppler signal obtained at the mitral valve leaflet tips.

\section{Strain analysis}

We used the TOMTEC Imaging Systems (Image Arena 4.6.3, Unterschleißheim, Germany) that is independent of ultrasound machines. The reliability of TOMTEC software for the measurement of LS on digitally stored images has been validated.[18, 19] Acquired images were stored in DICOM format. All analyses were performed by a single experienced cardiologist $(\mathrm{CH})$ blinded to clinical, genetic, LVEF, and outcome data. Longitudinal strain (LS) assessments of the LV were performed in the apical 4 chamber view, because cine loops in 3 or 2 chamber views were not available in the oldest exams. First, the cardiac cycle with the 
best image quality was selected and cardiac cycles were defined by the positioning of $\mathrm{R}$ waves. After manual tracing of three points designated by the software in the left ventricle on an endsystolic frame, the software automatically traced the endocardial border. Segments that failed to track were manually adjusted by the operator. Any view in which two or more segments could not be tracked was not included in the analysis. Peak systolic longitudinal strain was computed automatically, generating regional data from six segments (apical, mid, proximal) and an average value for the 4 chamber view (Figure 1).

The intra- and inter-observer variability for LS measurement was assessed in 22 participants of the study. For intra observer variability $(\mathrm{CH})$, analyses were repeated blinded to the initial results on the same cardiac cycles. Inter-observer variability was tested by a second observer (LL) blinded to the results of the first observer.

\section{Statistical analysis}

Continuous variables are presented as mean and standard deviations (SD) or median (interquartile range). By definition, LS was a negative number, but the absolute value of LS was used in the study. To measure the strength of association between LS and the other variables, Pearson's correlation was used for normally-distributed data; in case of non-normally data, Spearman's correlation was used. Baseline characteristics of the population were compared between living and deceased people using Student's t-test when Gaussian distribution occurred, or Mann-Whitney tests for non-Gaussian distribution. Categorical variables are presented as numbers and percentages, and are compared using Chi-square test p-values, or Fisher's test p-values when there were few events.

Kaplan-Meier curves were constructed and compared using the log-rank test.

Associations between any death and baseline parameters were assessed by using a multivariate Cox regression model. Unadjusted and adjusted models were performed for death; we included 
LVEF and GLS. Candidate covariables were selected for use in the multivariable model based on previous mortality studies and the rule of number of events per variable.

The two-sided significance level was fixed at 5\%. All tests were performed with SAS version 9.4 statistical software (SAS Institute Inc., Cary, NC, USA).

\section{RESULTS}

\section{Clinical characteristics of the population}

We identified 156 patients with standard echocardiogram and images digitally stored in 2D DICOM file format. Among these patients 140 had Longitudinal Strain (LS) and LVEF: LS was not available in 15 patients because of poor image quality (14), and persistent atrial fibrillation (1) and LVEF was not available in 1 patient. Characteristics of the 140 patients are presented in Table 1. Five patients carried point mutations in one of the two alleles. The shorter allele correlated with the larger allele $(\mathrm{r}=0.50 \mathrm{p}<.0001)$. As in previous studies, age at onset correlated with the length of the shorter GAA $(r=-0.56 \mathrm{p}<.0001)$ and of the longer GAA $(\mathrm{r}=-$ $0.42 \mathrm{p}<.0001)$, but in multivariate analysis the correlation was independent only for the shorter allele $(\mathrm{p}<.0001)$.

Nine patients $(6.4 \%)$ had previous paroxysmal or persistent atrial fibrillation, $4(2.9 \%)$ had previous symptoms of heart failure, and $1(0.7 \%)$ had previous stroke. At baseline, there were $7(5.0 \%)$ subjects with a diagnosis of diabetes and $11(7.9 \%)$ with a diagnosis of hypertension. The mean SARA score was 19.5 ranging from 9 to 39 for 21 (15\%) patients. At baseline, 20 $(14.3 \%)$ patients were on beta-blockers, $15(10.7 \%)$ on angiotensin converting enzyme inhibitors or angiotensin receptor blockers, 7 (6\%) on oral anticoagulants (vitamin K antagonist or new oral anticoagulant), $4(2.9 \%)$ on aspirin, 7 (5\%) on amiodarone, 4 (2.9\%) on diuretics, $2(1.4 \%)$ on spironolactone, and $1(0.7 \%)$ on digoxin.

ECG 
Cardiac involvement assessed by ECG was present in $89 \%$ of the patients with abnormal repolarization, and 27/140 (19\%) had a right bundle branch block (complete or incomplete).

\section{Echocardiographic variables}

Echocardiographic parameters are shown in Table 1. Left ventricular structural abnormalities, were observed with a concentric pattern assessed by a mean RWT of $0.50 \pm 0.13,105(75 \%)$ patients had RWT $>0.42$. Only 14 patients had SWT or PWT $\geq 13 \mathrm{~mm}$, and 2 patients $\geq 15 \mathrm{~mm}$. Mean LV mass index was $99 \pm 24 \mathrm{~g} / \mathrm{m}^{2}: 91 \pm 20 \mathrm{~g} / \mathrm{m}^{2}$ in 72 women and $108 \pm 26 \mathrm{~g} / \mathrm{m}^{2}$ in 68 men; LVMI was increased in 54/140 (39\%) patients: $25 / 68$ men had a LVMI $>115 \mathrm{~g} / \mathrm{m}^{2}$ and 29/72 women had a LVMI $>95 \mathrm{~g} / \mathrm{m}^{2}$. Left ventricle outflow tract obstruction was not observed. Mean LVEF was $64 \pm 8 \%$ and ranged from $26 \%$ to $80 \%$.

\section{Longitudinal strain}

The intra-observer coefficient of variation (CV) for longitudinal strain was $5.8 \%$ and the interobserver CV was 6.3\%. Mean LS was $19.9 \pm 5.0 \%$ and ranged from $5.9 \%$ to $31.2 \%$ (Figure 2). No relationship was found between LS and the SARA score. LS negatively correlated with the length of the shorter GAA repeats $(r=-0.23, p=0.0059)$ and with the length of the longer GAA repeats $(\mathrm{r}=-0.25, \mathrm{p}=0.0027)$, but the correlation was not independent in multivariate analysis for both alleles. LS correlated with LVEF $(r=0.31, p=0.0002)$ in total population and in patients with $\mathrm{LVEF}>50 \%(\mathrm{r}=0.26, \mathrm{p}=0.003)$. The $131 / 140(84 \%)$ patients with $\mathrm{LVEF}>50 \%$ had a mean LVEF of $65 \pm 5 \%$ and a mean LS of $20.4 \pm 4.6 \%$. The $9 / 140(6 \%)$ patients with a LVEF $\leq 50 \%$ had a mean LVEF of $41 \pm 7 \%$ and a mean LS of $12.0 \pm 3.7 \%$.

LS correlated with the echographic parameters reflecting hypertrophy: SWT $(r=-0.27, p=0.001)$ and LVMi $(\mathrm{r}=-0.18, \mathrm{p}=0.034)$, but no significant correlation was found with PWT, RWT, LVDD, and LVSD.

\section{Follow up}


After a mean follow up of $7.4 \pm 3.9$ years ranging from 0.4 to 14.7 years, 14 (10\%) patients died at a mean age of $33.0 \pm 7.8$ years: 10 from cardiovascular origin, 4 from unknown origin. No patient was lost to follow-up. During the follow-up, atrial fibrillation occurred in $12(8.6 \%)$ patients, heart failure in $6(4.3 \%)$, and stroke in $2(1.4 \%)$. No ventricular arrhythmia was reported. Patients who died during the follow up had younger age of disease onset and larger GAA repeats on the shorter allele, and they had at baseline lower LVEF and lower LS (Table $1)$.

\section{Survival analysis}

In the univariate Cox analysis all-cause mortality was associated with smaller LS (HR 0.83; 95\% CI 0.75-0391, $\mathrm{p}=0.0002$ ) and smaller LVEF (HR 0.30; 95\% CI 0.19-0.48, $\mathrm{p}<0.0001$ ). The other prognostic factors are shown in Table 2. Parameters reflecting the diastolic function, mitral peak A wave, the ratio E/A, and the left atria area were significantly associated with allcause mortality. In multivariate Cox analysis, LVEF was the only independent factor associated with all-cause mortality (HR 0.41; 95\% CI 0.23-0.74, $\mathrm{p}=0.0029$ ). If LVEF was not included as covariate, LS and shorter GAA were significantly associated with all-cause mortality: HR 0.87; 95\%CI, 0.79-0.96 p=0.0066 and HR 1.23; 95\%CI, 1.04-1.45 p=0.0164 respectively. If the multivariate model included the covariates LS and LVMi, only LS was associated with allcause mortality HR 0.85; 95\%CI, 0.77-0.94 p=0.0009.

In this population, the optimal cut-off of LS was $-15.4 \%$ and was determined based on the LS value that yielded the maximum value of Youden index. When dividing the population according to this cutoff value, 23 patients had LS $\leq 15.4 \%(11.8 \pm 2.8 \%)$ and 117 patients had LS $>15.4 \%(21.5 \pm 3.6 \%)$. Patients with LS $\leq 15.4 \%$ had a worse outcome $(p<0.0001)$ compared with patients with LS $>15.4 \%$ (Figure 3). When LVEF and LS were included in the multivariate analysis as subgroups (LS $\leq 15.4 \%$ and $\mathrm{LVEF} \leq 45 \%$ ), LVEF (HR 6.35; 95\% CI, 1.49-27.07, 
$\mathrm{p}=0.0125$ ).was associated with all-cause mortality but not LS (HR 3.40; 95\% CI, 0.86-13.47, $\mathrm{p}=0.0821)$.

Among the 131 patients with LVEF $>50 \%, 8$ deaths occurred during the mean follow up of 7.6 \pm 3.8 years. LS was not different between patients who died and the others: $17.1 \pm 7.8 \%$ and $20.6 \pm 4.3 \%$ respectively, $\mathrm{p}=0.28$. In univariate Cox analysis, LS was not significantly associated with all-cause mortality: LS (HR 0.89; 95\%CI, 0.79-1.02, p=0.0899). Similar results were obtained when we studied the 133 patients with LVEF $>45 \%$ with $9(6.8 \%)$ deaths observed during the follow up.

\section{Discussion}

This study is the first to evaluate the prognostic value of longitudinal strain (LS) assessed by two-dimensional echocardiography in a large cohort of Friedreich's ataxia adult patients. We demonstrated that LS was a strong prognostic factor in univariate analysis, but was not an independent predictor of all-cause mortality when LVEF was included in the analysis. In the present study the superiority of LVEF could be explained by the significant correlation between longitudinal strain and LVEF, and by the larger amplitude of variation of LVEF between FA patients who died and surviving patients. These results are not in accordance with previous studies where longitudinal strain appeared to provide stronger prognostic information than LVEF in different diseases.[11, 20] It was especially demonstrated in individuals with preserved ejection fraction.[20, 21] In the $131 \mathrm{FA}$ patients with LVEF $>50 \%$, LS tended to be associated with all-cause mortality, but too few events occurred in this group of patients to confirm the prognostic value of longitudinal strain in FA patients with preserved ejection fraction.

An important finding of this study is that LS appeared to be significantly correlated with the length of both alleles of the $F X N$ gene: greater genetic severity might be associated with lower strain values. Such a relation was previously suggested by St John Sutton et al.[14] We can 
hypothesize that decreased longitudinal strain may reflect lack of frataxin and impaired mitochondrial function in the heart. However the weak correlation between GAA repeats and LS suggested that others factors are involved in LS value of these patients.

Cardiac remodeling is thought to represent a compensatory process to mitochondrial dysfunction in FA. In the present study, LS was weakly negatively correlated with septal wall thickness and left ventricular mass index. However the relations between myocardial hypertrophy and longitudinal strain remain unclear in the disease. It was previously reported in 27 FA children that LS was similar in patients with septal wall thickness smaller or larger than $12 \mathrm{~mm} \cdot[14]$

Dedobbeleer et al demonstrated that global longitudinal strain was reduced $(15.3 \pm 2.1 \%)$ in a small group of $20 \mathrm{FA}$ patients with a typical concentric remodeling pattern and normal LVEF, compared to age and sex matched healthy individuals.[13] In our study, mean LS assessed in apical four chamber was lower $(19.9 \pm 5.0 \%)$ than the mean reference values $(22.6 \pm 3 \%)$ reported in healthy subjects in the European NORRE study, but remained in the normal range defined by this study.[19] Patients who died during our study had significantly lower LS and LVEF compared to the survivors: $12.9 \%$ versus $20.6 \%$ and $59 \%$ versus $64 \%$ respectively. In the MICONOS study performed in 205 FA patients, Weidemann et al reported lower levels of longitudinal strain in FA subjects with more severe disease: $-16.4 \pm 2.9 \%$ in patients classed as not having a cardiomyopathy with normal LVEF of $65 \%$ and normal wall thickness (mean septal wall thickness of $0.89 \mathrm{~cm}),-15.3 \pm 3.1 \%$ in patients with mild cardiomyopathy with a normal LVEF of $65 \%$ and mild hypertrophy (SWT of $1.11 \mathrm{~cm}$ ), $-13.3 \pm 3.4 \%$ in patients with intermediate cardiomyopathy with normal LVEF of $65 \%$ and intermediate hypertrophy (SWT of $1.38 \mathrm{~cm}$ ), and $-12.8 \pm 3.9 \%$ in patients with severe cardiomyopathy with altered LVEF (53\%).[7] In Friedreich's ataxia, the rate and nature of progression to left ventricular dysfunction and heart failure are highly variable. Therefore longitudinal strain is likely to reflect 
left ventricular dysfunction, while longitudinal function is primarily involved before the alteration of LV ejection fraction. Longitudinal strain could be proposed as an early parameter to follow to detect subtle LV dysfunction in these patients.

We can speculate that in FA, longitudinal strain decreased when myocardial fibrosis appeared, as was demonstrated in hypertrophic cardiomyopathy.[22] The presence of myocardial fibrosis is likely to be an important feature during the progression of the cardiac disease and may play a role in prognosis in these patients.

This study did not provide evidence for an association between neurologic and cardiac involvement assessed by longitudinal strain.

\section{Limitations}

We did not assess global radial and circumferential strain analyses, because they are not sufficiently reproducible for routine clinical work, despite demonstrated utility in research studies in FA.[14]

In this study, retrospective LS analysis in apical 4 chamber view was possible in only $90 \%$ of the patients for technical reasons. Longitudinal strain measurement is dependent on high quality 2D images and appropriate imaging settings, and could not be performed in all FA subjects. Strain analysis was assessed from stored DICOM images, but storing images does not significantly compromise analysis of global strain measurements.[18] LS values reported in this study cannot be assumed to apply to other echocardiographic platforms.

In this retrospective study, we were able to assess longitudinal strain in single apical 4 chambers view, because apical 2 or 3 chamber views were not available for all patients. It would have been of particular interest to study the inferolateral wall, which may be affected at an earlier stage than other walls in FA. [7]

Although there is a good correlation in diffuse process between GLS using the 3 chamber apical long axis views and single view longitudinal strain measurement [23], GLS calculated from 3 
apical views should actually remain the preferred method for evaluation of longitudinal strain in FA.

\section{In conclusion,}

Left ventricular strain analysis by $2 \mathrm{D}$ echocardiography speckle tracking is a simple and feasible method available in standard ultrasound machines and is now routine practice in many echocardiographic laboratories. Longitudinal strain assessed in one single view provides prognostic information, but LVEF remains a stronger prognostic factor in Friedreich's Ataxia. Moreover, serial measurements are needed to characterize the temporal course of longitudinal strain and the relationship to the evolution of LVEF. Longitudinal studies are necessary to confirm the prognostic value of global longitudinal strain in FA and to clarify the most appropriate cut-off values that predict greater risk. These additional studies could allow for definition of the role of longitudinal strain in the management of FA in clinical practice.

\section{Acknowledgment}

The authors would like to thank all patients who participated in the study and the French Friedreich Ataxia Association (AFAF) for a grant (2016).

Special thanks go to Marie Biet who helped with data management and to Charlotte Lellman for English editing. 
Table 1: Baseline characteristics of 140 patients with Friedreich ataxia

\begin{tabular}{|c|c|c|c|c|}
\hline & $\begin{array}{l}\text { Population } \\
\qquad N=140\end{array}$ & $\begin{array}{l}\text { Death } \\
\mathrm{N}=14\end{array}$ & $\begin{array}{l}\text { Alive } \\
\mathrm{N}=126\end{array}$ & P value \\
\hline Age (years) & $34(2.6-41)$ & $33(27-39)$ & $34(25-41)$ & ns \\
\hline Age at onset (years) & $14(11-19)$ & $10(9-12)$ & $15(12-21)$ & 0.0020 \\
\hline Duration of symptoms (years) & $16(11-23)$ & $19(16-23)$ & $15(10-23)$ & 0.0726 \\
\hline Age at onset of wheelchair use (years), N=109 & $23(18-29)$ & $17(15-24)$ & $24(20-30)$ & 0.0104 \\
\hline 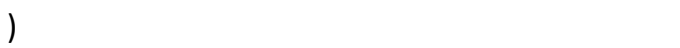 & & & & \\
\hline GAA repeats on the shorter allele (pb) & $600(467-783)$ & $800(667-867)$ & $600(433-767)$ & 0.0008 \\
\hline GAA repeats on the longer allele (pb) & $867(767-1000)$ & $1017(833-1100)$ & $833(733-1000)$ & 0.0172 \\
\hline Body mass index $\left(\mathrm{kg} / \mathrm{m}^{2}\right)$ & $21.8(19.5-23.9)$ & $22.2(19.1-23.8)$ & $21.8(19.6-23.9)$ & ns \\
\hline Body surface area $\left(\mathrm{m}^{2}\right)$ & $1.7(1.6-1.8)$ & $1.7(1.5-1.8)$ & $1.7(1.6-1.8)$ & ns \\
\hline Systolic blood pressure (mmHg) & $117 \pm 15$ & $105 \pm 14$ & $119 \pm 14)$ & 0.0018 \\
\hline Diastolic blood pressure (mmHg) & $71 \pm 9$ & $65 \pm 9$ & $72 \pm 9$ & 0.0220 \\
\hline Heart rate (bpm) & $77 \pm 12$ & $77 \pm 14$ & $77 \pm 12$ & ns \\
\hline Longitudinal Strain (\%) & $20.2(17.2-22.7)$ & $12.9(8.7-20.0)$ & $20.6(17.7-22.8)$ & 0.0015 \\
\hline LV Ejection Fraction (\%) & $64(60-68)$ & $59(42-65)$ & $64(61-69)$ & 0.0080 \\
\hline Septal Wall Thickness (mm) & $11.4 \pm 2.4$ & $12.6 \pm 2.7$ & $11.3 \pm 2.3$ & 0.0080 \\
\hline Posterior Wall Thickness (mm) & $10.4 \pm 1.8$ & $10.1 \pm 2.4$ & $10.5 \pm 1.8$ & 0.0661 \\
\hline Relative Wall Thickness & $0.50 \pm 0.13$ & $0.51 \pm 0.18$ & $0.50 \pm 0.12$ & ns \\
\hline LV End Diastolic Diameter (mm) & $43.8(40.1-48.2)$ & $46.7(41.0-50.6)$ & $43.5(40.1-47.7)$ & ns \\
\hline LV End Systolic Diameter (mm) & $26.2(23-30.4)$ & $31.9(25-37.6)$ & $26.0(22.9-29.8)$ & 0.0213 \\
\hline LV Mass index $\left(\mathrm{g} / \mathrm{m}^{2}\right)$ & $99 \pm 24$ & $113 \pm 27$ & $98 \pm 24$ & 0.0250 \\
\hline LV Mass index male $\left(\mathrm{g} / \mathrm{m}^{2}\right)$ & $108 \pm 26$ & & & \\
\hline LV Mass index female $\left(\mathrm{g} / \mathrm{m}^{2}\right)$ & $91 \pm 20$ & & & \\
\hline Transmitral E wave (cm/sec) & $0.72 \pm 0.15$ & $0.70 \pm 0.13$ & $0.72 \pm 0.15$ & ns \\
\hline Transmitral A wave $(\mathrm{cm} / \mathrm{sec})$ & $0.52(0.43-0.62)$ & $0.34(0.24-0.47)$ & $0.53(0.44-0.63)$ & 0.0002 \\
\hline E/A ratio & $1.4(1.1-1.7)$ & $2.1(1.4-3.3)$ & $1.4(1.1-1.7)$ & 0.0025 \\
\hline
\end{tabular}




\begin{tabular}{|c|c|c|c|c|}
\hline & $\begin{array}{c}\text { Population } \\
\mathrm{N}=\mathbf{1 4 0}\end{array}$ & $\begin{array}{l}\text { Death } \\
N=14\end{array}$ & $\begin{array}{c}\text { Alive } \\
\mathrm{N}=126\end{array}$ & $P$ value \\
\hline Left atrial area $\left(\mathrm{cm}^{2}\right)$ & $15(12-18)$ & $15(13-23)$ & $15(12-18)$ & ns \\
\hline Previous Heart failure & $4(2.9 \%)$ & $4(28.6 \%)$ & 0 & $<.0001$ \\
\hline Previous stroke & $1(0.7 \%)$ & 0 & $1(0.8 \%)$ & ns \\
\hline Previous atrial fibrillation & $9(6.4 \%)$ & $4(28.6 \%)$ & $5(4 \%)$ & 0.0061 \\
\hline Hypertension & $11(7.9 \%)$ & $1(7.1 \%)$ & $10(7.9 \%)$ & ns \\
\hline Diabetes & $7(5 \%)$ & $3(21.4 \%)$ & $4(3.2 \%)$ & 0.0222 \\
\hline
\end{tabular}

Data are expressed as mean \pm SD or median (interquartile range) 
Figure 1: Longitudinal strain (LS) measurement from 4-chamber apical view with Tomtec software(a) Example of tracking for the segments measured. (b) Peak longitudinal strain value (\%) for each segment measured and the average is Longitudinal Strain (LS). (c) Peak strain in each segment is presented graphically.

Figure 2: Distribution of Longitudinal strain (LS) in 140 patients with Friedreich ataxia median LS $=20.2 \%(17.2-22.7)$

Figure 3: Unadjusted Kaplan-Meier curve for individuals using LS cutoff in 140 patients with Friedreich ataxia 
Table 2: Survival analysis in 140 patients with Friedreich ataxia and factors associated with all-cause mortality

\begin{tabular}{|c|c|c|c|c|c|c|}
\hline \multirow[b]{3}{*}{ Variables } & \multirow{2}{*}{\multicolumn{3}{|c|}{ Univariate Cox model }} & \multirow{2}{*}{\multicolumn{2}{|c|}{ Multivariate Cox Model }} & \\
\hline & & & & & & \multirow[b]{2}{*}{ P-value } \\
\hline & $\mathbf{N}$ & Hazard-ratio(95\% Cl) & P-value & $\mathbf{N}$ & Hazard ratio(95\% Cl) & \\
\hline Longitudinal strain (\%) & 140 & $0.83(0.75-0.91)$ & 0.0002 & 140 & $0.91(0.81-1.03)$ & 0.1375 \\
\hline LV ejection fraction (units=10\%) & 140 & $0.30(0.19-0.48)$ & $<.0001$ & 140 & $0.41(0.23-0.74)$ & 0.0029 \\
\hline Age (years) & 140 & $0.98(0.93-1.04)$ & 0.5005 & & & \\
\hline Age at onset (years) & 139 & $0.87(0.77-0.98)$ & 0.0176 & & & \\
\hline GAA repeats on the shorter allele & 140 & $1.29(1.10-1.51)$ & 0.0018 & & & \\
\hline (units $=50 \mathrm{pb}$ ) & & & & & & \\
\hline LV Mass index $\left(g / m^{2}\right)$ & 140 & $1.02(1.00-1.04)$ & 0.0270 & & & \\
\hline Sex Female & 140 & $1.73(0.58-5.16)$ & 0.3283 & & & \\
\hline Body mass index $\left(\mathrm{kg} / \mathrm{m}^{2}\right)$ & 140 & $0.98(0.83-1.17)$ & 0.8309 & & & \\
\hline Septal wall thickness (mm) & 140 & $1.20(0.98-1.46)$ & 0.0844 & & & \\
\hline LV end diastolic diameter (mm) & 140 & $1.12(1.01-1.23)$ & 0.0283 & & & \\
\hline LV end systolic diameter (mm) & 138 & $1.17(1.09-1.26)$ & $<.0001$ & & & \\
\hline Posterior wall thickness (mm) & 140 & $0.88(0.65-1.19)$ & 0.4096 & & & \\
\hline Relative wall thickness & 140 & $0.87(0.01-73.1)$ & 0.9516 & & & \\
\hline Mitral E wave $(\mathrm{cm} / \mathrm{sec})$ & 138 & $0.92(0.65-1.32)$ & 0.6621 & & & \\
\hline Mitral A wave (cm/sec) & 138 & $0.45(0.30-0.68)$ & $0 . .0001$ & & & \\
\hline Mitral E/A ratio & 138 & $1.28(1.16-1.42)$ & $<.0001$ & & & \\
\hline Left atrial area $\left(\mathrm{cm}^{2}\right)$ & 139 & $1.13(1.01-1.26)$ & 0.0333 & & & \\
\hline
\end{tabular}




\section{References}

1. Durr A, Cossee M, Agid $\mathrm{Y}$ et al. Clinical and genetic abnormalities in patients with Friedreich's ataxia. N Engl J Med 1996; 335: 1169-75.

2. Campuzano V, Montermini L, Molto MD et al. Friedreich's ataxia: autosomal recessive disease caused by an intronic GAA triplet repeat expansion. Science 1996; 271: 1423-7.

3. Reetz K, Dogan I, Costa AS et al. Biological and clinical characteristics of the European Friedreich's Ataxia Consortium for Translational Studies (EFACTS) cohort: a cross-sectional analysis of baseline data. Lancet Neurol 2015; 14: 174-82.

4. Reetz K, Dogan I, Hilgers RD et al. Progression characteristics of the European Friedreich's Ataxia Consortium for Translational Studies (EFACTS): a 2 year cohort study. Lancet Neurol 2016; 15: 1346-54.

5. Tsou AY, Paulsen EK, Lagedrost SJ et al. Mortality in Friedreich ataxia. J Neurol Sci 2011; 307: 46-9.

6. Pousset F, Legrand L, Monin ML et al. A 22-Year Follow-up Study of Long-term Cardiac Outcome and Predictors of Survival in Friedreich Ataxia. JAMA Neurol 2015; 72: 1334-41.

7. Weidemann F, Rummey C, Bijnens B et al. The heart in Friedreich ataxia: definition of cardiomyopathy, disease severity, and correlation with neurological symptoms. Circulation 2012; 125: 1626-34.

8. Marwick TH, Shah SJ, Thomas JD. Myocardial Strain in the Assessment of Patients With Heart Failure: A Review. JAMA Cardiol 2019; 4: 287-94.

9. D'Elia N, Caselli S, Kosmala W et al. Normal Global Longitudinal Strain: An Individual Patient Meta-Analysis. JACC Cardiovasc Imaging 2020; 13: 167-9.

10. Brown J, Jenkins C, Marwick TH. Use of myocardial strain to assess global left ventricular function: a comparison with cardiac magnetic resonance and 3-dimensional echocardiography. Am Heart J 2009; 157: 102 e1-5.

11. Stanton T, Leano R, Marwick TH. Prediction of all-cause mortality from global longitudinal speckle strain: comparison with ejection fraction and wall motion scoring. Circ Cardiovasc Imaging 2009; 2: 356-64.

12. Mottram PM, Delatycki MB, Donelan L et al. Early changes in left ventricular long-axis function in Friedreich ataxia: relation with the FXN gene mutation and cardiac structural change. $\mathrm{J} \mathrm{Am}$ Soc Echocardiogr 2011; 24: 782-9.

13. Dedobbeleer C, Rai M, Donal E et al. Normal left ventricular ejection fraction and mass but subclinical myocardial dysfunction in patients with Friedreich's ataxia. Eur Heart J Cardiovasc Imaging 2012; 13: 346-52.

14. St John Sutton M, Ky B, Regner SR et al. Longitudinal strain in Friedreich Ataxia: a potential marker for early left ventricular dysfunction. Echocardiography 2014; 31: 50-7. 
15. Marelli C, Figoni J, Charles $P$ et al. Annual change in Friedreich's ataxia evaluated by the Scale for the Assessment and Rating of Ataxia (SARA) is independent of disease severity. Mov Disord 2012; 27: 135-8.

16. Lang RM, Bierig M, Devereux RB et al. Recommendations for chamber quantification: a report from the American Society of Echocardiography's Guidelines and Standards Committee and the Chamber Quantification Writing Group, developed in conjunction with the European Association of Echocardiography, a branch of the European Society of Cardiology. J Am Soc Echocardiogr 2005; 18: 1440-63.

17. Foppa M, Duncan BB, Rohde LE. Echocardiography-based left ventricular mass estimation. How should we define hypertrophy? Cardiovasc Ultrasound 2005; 3: 17.

18. Risum N, Ali S, Olsen NT et al. Variability of global left ventricular deformation analysis using vendor dependent and independent two-dimensional speckle-tracking software in adults. J Am Soc Echocardiogr 2012; 25: 1195-203.

19. Sugimoto $T$, Dulgheru R, Bernard A et al. Echocardiographic reference ranges for normal left ventricular 2D strain: results from the EACVI NORRE study. Eur Heart J Cardiovasc Imaging 2017; 18: 833-40.

20. Kalam K, Otahal P, Marwick TH. Prognostic implications of global LV dysfunction: a systematic review and meta-analysis of global longitudinal strain and ejection fraction. Heart 2014; 100: 1673-80.

21. Hiemstra YL, Debonnaire P, Bootsma M et al. Global Longitudinal Strain and Left Atrial Volume Index Provide Incremental Prognostic Value in Patients With Hypertrophic Cardiomyopathy. Circ Cardiovasc Imaging 2017; 10.

22. Haland TF, Almaas VM, Hasselberg NE et al. Strain echocardiography is related to fibrosis and ventricular arrhythmias in hypertrophic cardiomyopathy. Eur Heart J Cardiovasc Imaging 2016; 17: 613-21.

23. Thavendiranathan P, Negishi T, Cote MA et al. Single Versus Standard Multiview Assessment of Global Longitudinal Strain for the Diagnosis of Cardiotoxicity During Cancer Therapy. JACC Cardiovasc Imaging 2018; 11: 1109-18. 


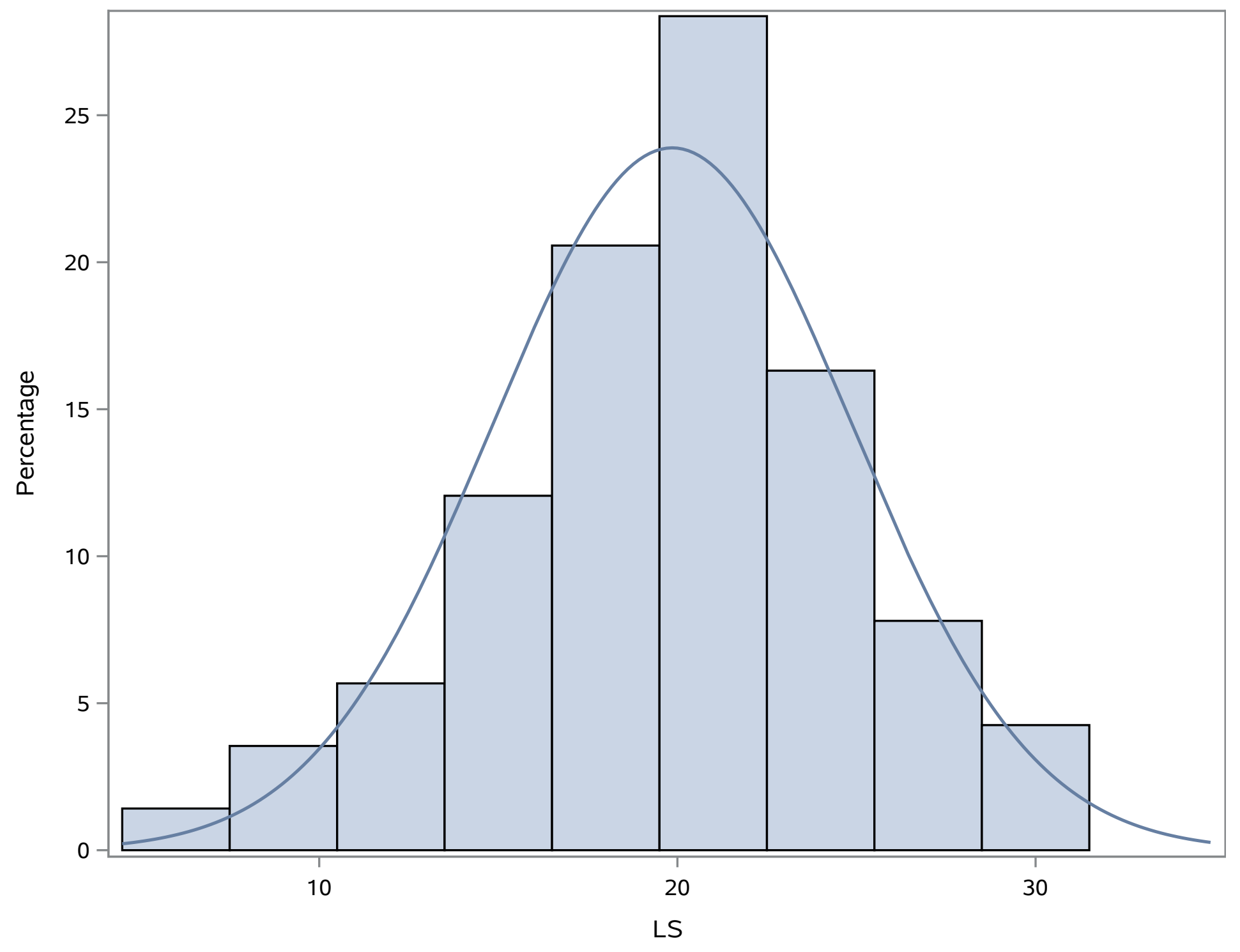


$? \times$

Transverse Strain

03-basal inflsept

03-basal inf/se

09-mid inf/sept

14-apical septa

16-apical latera

12-mid ant/lat

06 -basal ant/la

Average

$\begin{array}{lll}10.1 & 6.2 & 467\end{array}$

$\begin{array}{lll}33.2 & 30.7 & 334\end{array}$

$\begin{array}{lll}35.2 & 33.2 & 334\end{array}$

$\begin{array}{lll}30.9 & 29.7 & 367\end{array}$

30.929 .7

$49.4 \quad 48.0$

$101.3101 .3 \quad 400$

$421 \quad 41.5$

g Wall Delay : $67 \mathrm{~ms}$

$013 / 37$ 7033/0400/1233 ms. (493bpm)15 06:37:03AM tis0.3 M10.9 ER 51Hz 47240620150409

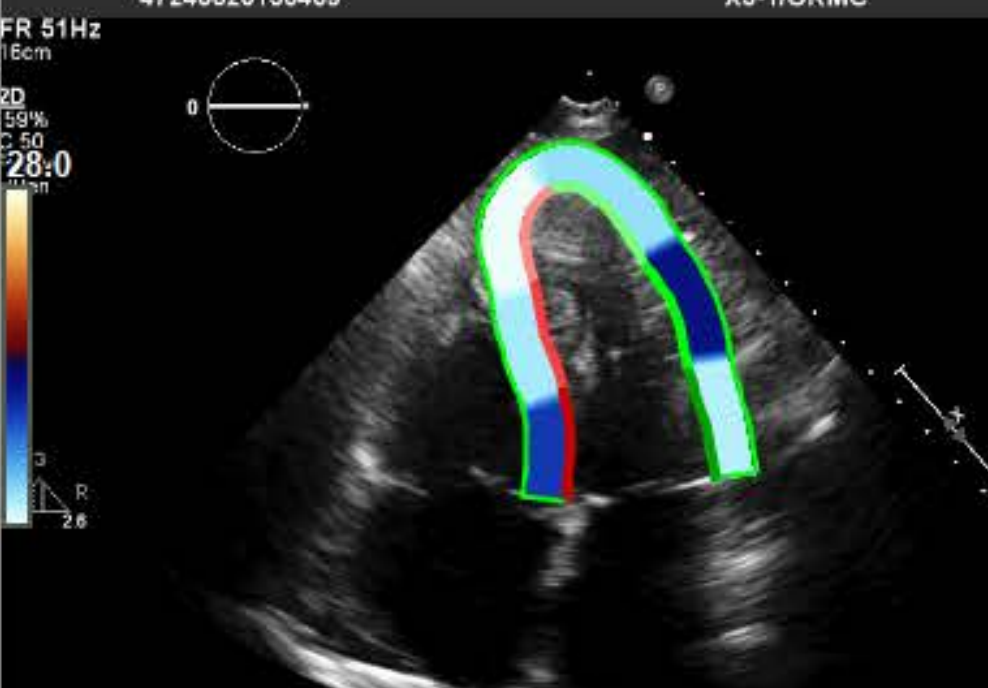

$$
\text { in }
$$

Longitudinal Strain (endo) 49 bpm Longitudinal Strain (endo ) Seg

ES TTP $\mathrm{ms}$

09-mid inf/sept $\quad-24.0 \quad-22.4$

14-apical septal $\quad-27.9 \quad-27.3$

16-apical lateral $\quad-22.8 \quad-21.6$

12-mid ant/lat $\quad-4.7 \quad-3.8$

06 -basal ant/lat $\quad-25.0 \quad-24.8$

Average

$\begin{array}{lll}-25.0 & -24.8 & 434 \\ -18.8 & -18.2 & 367\end{array}$

Maximum Opposing Wall Delay : $33 \mathrm{~ms}$

es-gls endo $-18.22 \%$

es-gls myo $-13.83 \%$

es-gcs endo $-28.68 \%$

es-gcs myo $-17.37 \%$

467

334

367

367

334

\section{- Velocity}

- Displacement

- Strain

- Strain Rate
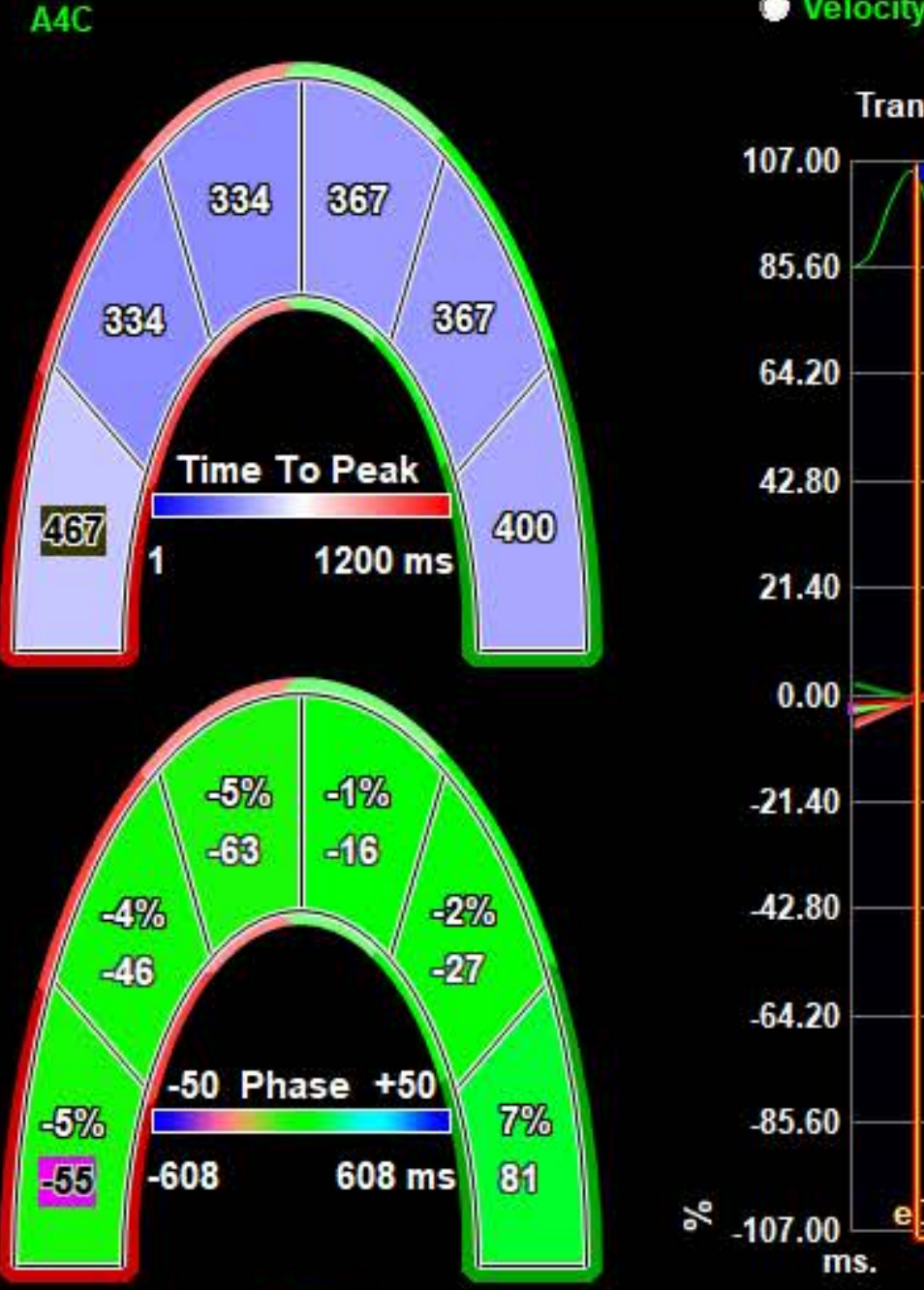

sverse Strain

$\therefore-107.00$ ms.

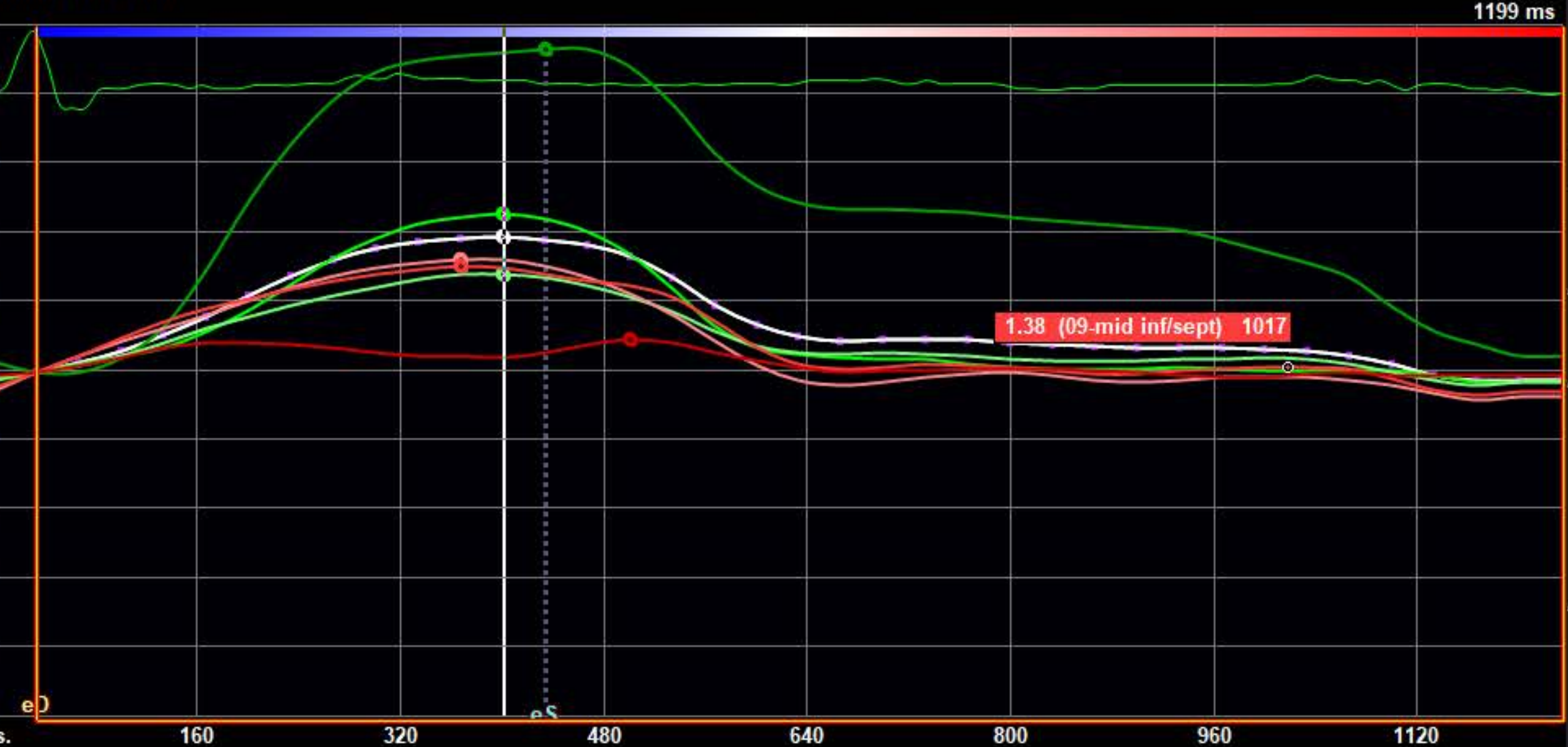

Longitudinal Strain (endo)

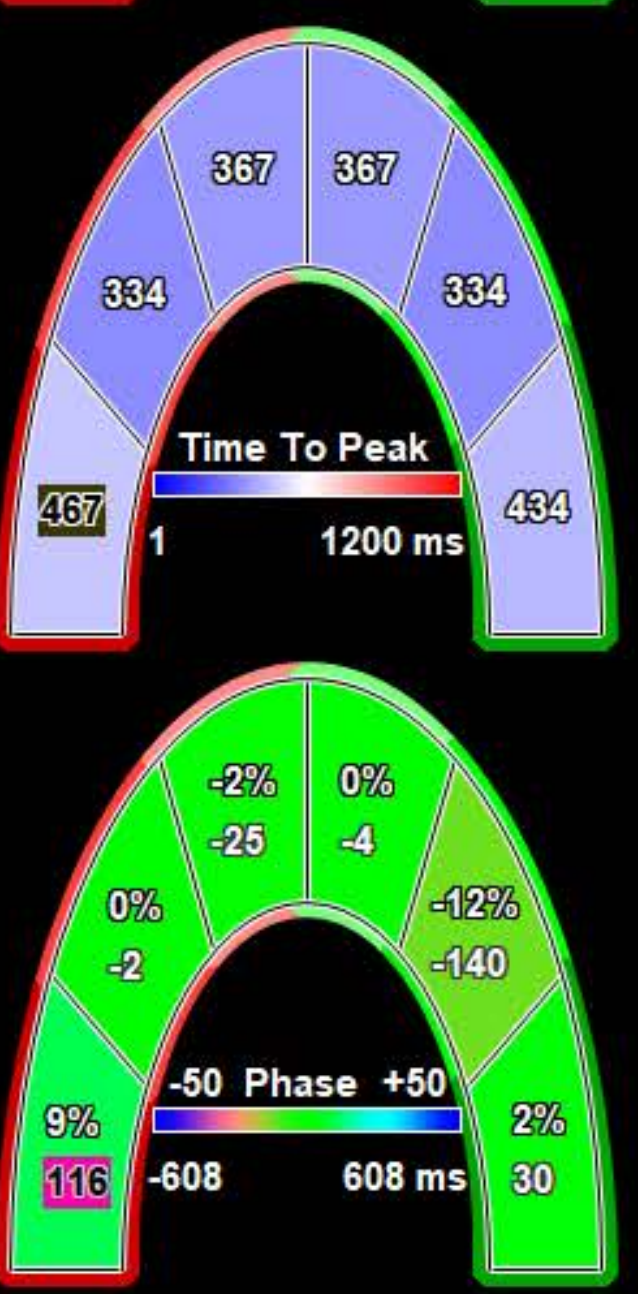

$1199 \mathrm{~ms}$

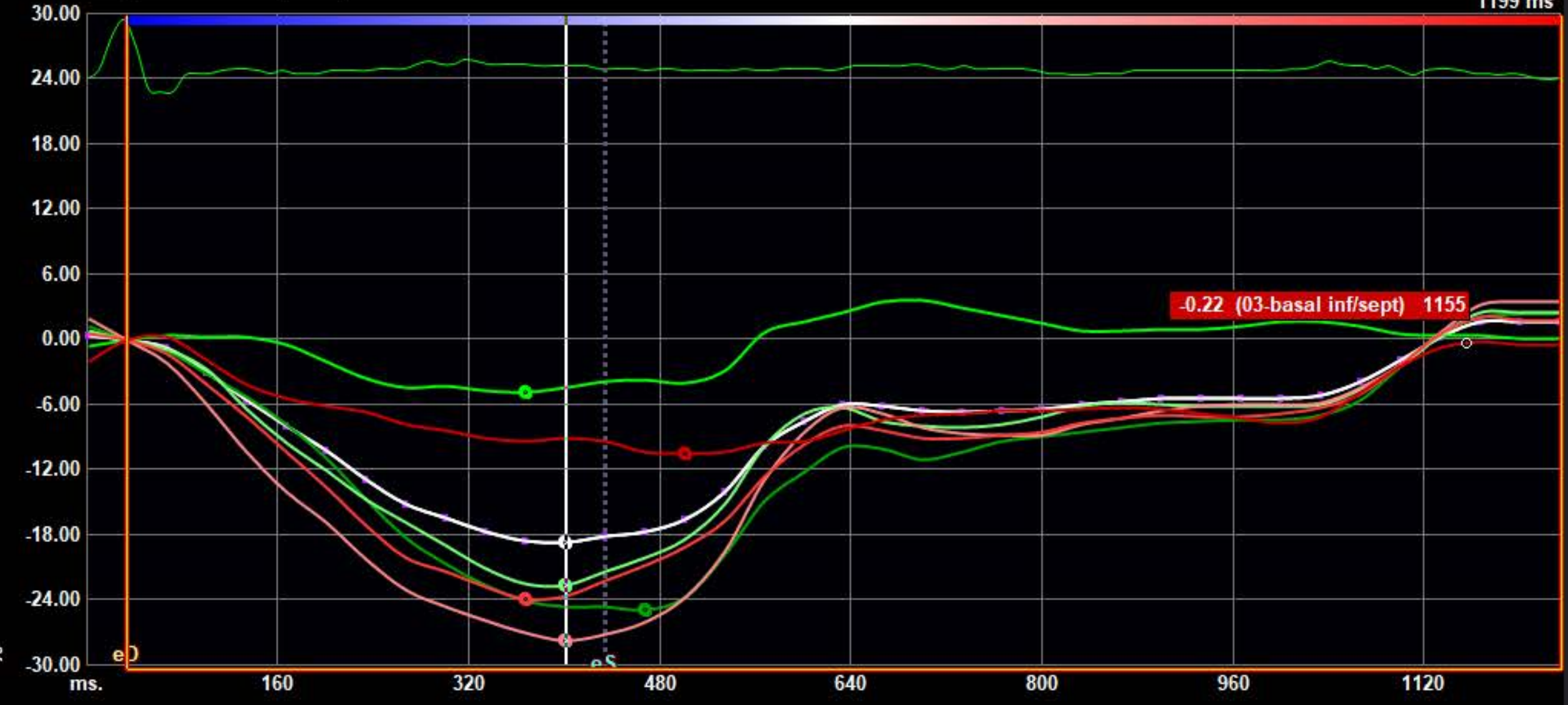

Average $X$

Reverse Peak

Padial

Long/Rot 


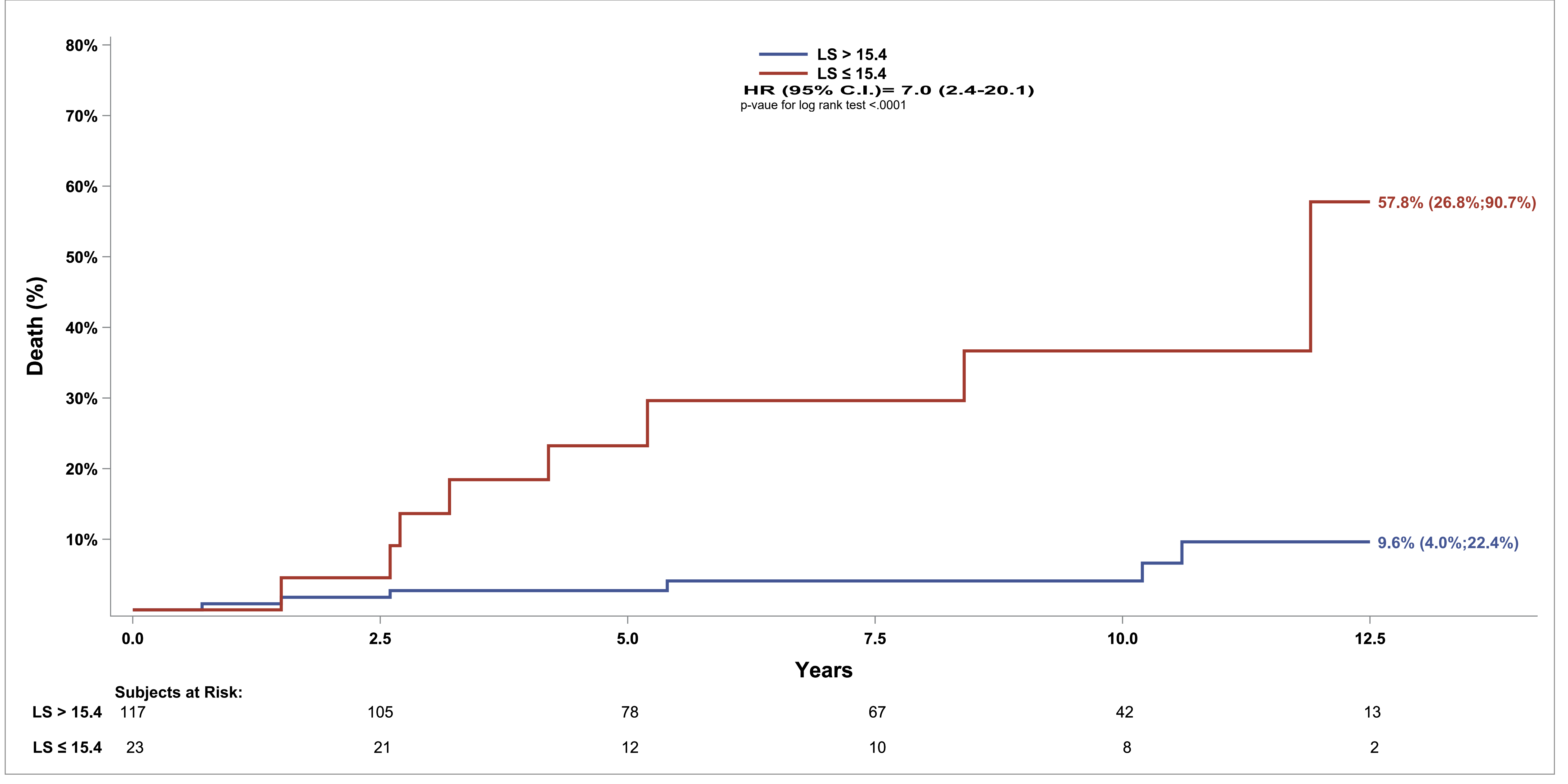

